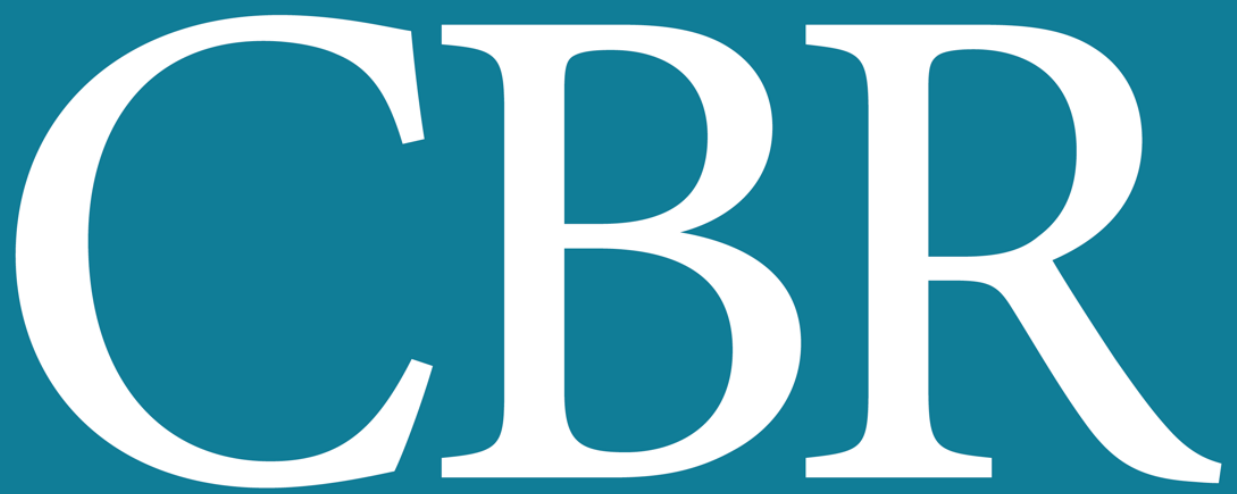

INTERNATIONAL JOURNAL OF CANCER AND BIOMEDICAL RESEARCH

https://jcbr.journals.ekb.eg

Editor-in-chief

Prof. Mohamed Labib Salem, PhD

Enhancement of immune tolerance of COVID19 patients might be achieved with alginate supplemented therapy

Amany El-Sikaily, Mohamed Helal, Aziza Saad 


\section{International Journal of Cancer \& Biomedical Research \\ (IJCBR) https://jcbr.journals.ekb.eg}

IJCBR is an Int. journal published by the Egyptian Society of Cancer Research (EACR, established in 2014, http://eacr.tanta.edu.eg) and sponsored by the Egyptian Knowledge Bank (EKB: www.ekb.eg).

IJCBR has been approved by the Supreme Council of Universities, Egypt with score 7 (http://egjournal.scu.eg). The journl is cited by google scholar and registered by Publons (https://publons.com). The journal has recently been evaluated in 2020 by Nature Springer with a good standing.

\section{Scope of IJCBR}

- Drug discovery from natural and synthetic resources

- BioMedical applications of nanotehnology

- Sem cell biology and its application

- Basic and applied biotechnology

- Inflammation and autoimmune diseases

- In slico models and bioinformatics

- In vitro and In vivo preclinical animal models

- Cellular and molecular cancer biology

- Cancer Immunology and Immunotherapy

- New methods for prediction, early detection, diagnosis prognosis and treatment of dieases.

- Immunology in health and dieases

- Anti-microbial defense mechanisms

- Cellular and molecular physhiology and pahthology of diseases

\section{IJCBR Editor,}

Prof. Mohamed Labib Salem, PhD

Professor of Immunology

Faculty of Science, Tanta Universiy, Egypt 


\title{
Enhancement of immune tolerance of COVID-19 patients might be achieved with alginate supplemented therapy
}

\author{
Amany El-Sikaily ${ }^{1}$, Mohamed Helal ${ }^{1}$, Aziza Saad ${ }^{2}$ \\ ${ }^{1}$ National Institute of Oceanography and Fisheries, Alexandria, Egypt \\ ${ }^{2}$ Medical Research Institute, Elhorria Avenue, Alexandria, Egypt
}

\section{IIII}

ABSTRACT

\section{ARTICLE INFO}

Severe acute respiratory syndrome coronavirus 2 (SARS-CoV-2) is a devastating pandemic virus that has neither an effective cure nor vaccine so far. Once inside the body, blood viremia increases significantly in conjunction with uncontrolled awry immune response that induces severe unbalanced cytokine storm. This cytokine storm is initiated although the number of $T$ lymphocyte is severely reduced alongside damaged lymphoid tissue and systemic body inflammation. It will be a demanding need to find a natural polymer that has both anti-inflammatory and immune-enhancing effects that can induce the immune system to fight off the virus in a balanced manner. Alginate is a natural polysaccharide extracted from brown Algae and has been used extensively as an immune activator in different in vivo model animals and in vitro cell culture systems. Based on our recent experiment and other findings cited in the literature, we propose the introduction of alginate in the therapeutic regime of COVID-19 patients.

Keywords: Alginate, COVID-19, T lymphocyte, cytokine storm

Editor-in-Chief: Prof. M.L. Salem, PhD - Article DOI: 10.21608/jcbr.2020.28938.1033

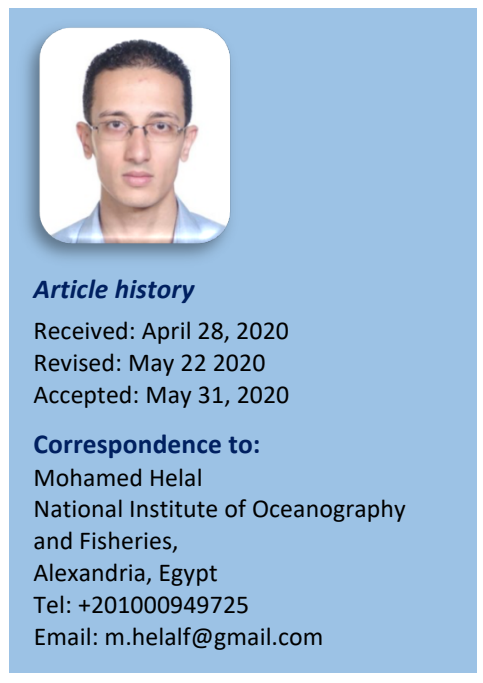

\section{INTRODUCTION}

The recent declaration of WHO of Severe acute respiratory syndrome coronavirus 2 (SARS-CoV2) as a pandemic was imposed by the widespread of the virus in almost every country in the world. SARS-CoV-2 is a positive singlestranded RNA virus that was naturally mutated to infect human from its intermediate hosts (bats and pangolins) (Letko et al., 2020; Zhang, 2020). Major concerns of SARS-CoV-2 in relation to other viruses are that firstly, SARS-CoV-2 infection appears before first symptom onset hit, secondly, up to $56 \%$ of patients experience no fever or other related symptoms and require no hospitalization finally a strict quarantine measure is the only solution to decrease viral spread (Ho, 2020). SARS-CoV-2 exhibit several structural and non-structural proteins that antagonize host antiviral immune response (antagonize interferons INFs), evade host immune system and promote its replication (Channappanavar et al., 2017; Zmmer, 2020).
Symptoms of SARS-CoV-2 infection include dyspnea, severe respiratory distress, hypoxemia, lymphopenia, exaggerated cytokine release known as cytokine storm (awry and excessive uncontrolled inflammatory cytokine production) and micro blood clotting in lungs and several body organs. These symptoms indicate that immune system homeostasis plays an important and significant role during viral pathogenesis and pneumonia development (Jiang et al., 2020; Li et al., 2020; Zheng et al., 2020). Several coronavirus disease (COVID-19) patients experience an exaggerated and uncontrolled release of cytokines although suffering lymphopenia. Analysis of $T$ lymphocytes in those patients indicated that these $T$ cells show high levels of exhaustion (high expression levels of Tim-3 and PD-1 markers) and show signs of reduced diversity (Ho, 2020; Zheng et al., 2020). This in part could explain the uncontrolled release of cytokines and the initiation of cytokine storm niche in lungs first and whole body lastly. 
A rapid reduction in $\mathrm{T}$ cell lymphocytes $\left(\mathrm{CD} 4^{+}\right.$ and $\mathrm{CD}^{+}$) was observed in SARS-COV-2 patients shortly after contradicting the virus. Although reduced in number, yet they exhibited elevated levels of CD69, CD38 and CD44 which are markers of $\mathrm{T}$ cell hyper-activation. This loss in $\mathrm{T}$ cell density was compensated during the recovery phase of patients and this was not due to new cells production from thymus but due to lymphocyte recirculation between body tissues and peripheral blood. This indicates that SARSCoV-2 infection could interfere with lymphocyte production in lymphoid organs with unknown mechanism. Consisting with this, reports from COVID-19 patients in China revealed that sever infected patients suffer from lymphoid tissues destruction (spleen atrophy, lymph node atrophy and necrotic foci all over the body) (Wen Zhang et al., 2019). Since immune cells and lymphoid tissues exhibit no ACE2 surface markers, it was postulated that $\mathrm{T}$ cell depletion as a direct consequence of inflammation and cytokine storm initiated by a viral infection (Wen Zhang \& Yan, 2019).

Viral induced inflammation was accompanied with significantly elevated levels of inflammatory cytokines such as IL-6, IL-7, IL-10, TNF- $\alpha$, granulocyte-colony stimulating factor(GCSF), monocyte chemoattractant protein 1 (MCP1) and macrophage inflammatory protein 1 alpha (MIP1A) was confirmed in those patients (Ho, 2020; Lin et al., 2020).

The proposed therapeutic regime in different countries was based on the use of anti-viral drugs along with anti-inflammatory drugs. Chloroquine and hydroxy-chloroquine were used as anti-inflammatory drugs in different countries before its withdrawal due to associated heart complications (Choudhary et al., 2020; Molina et al., 2020). In addition, UK recently approved the use of dexamethasone as an efficient anti-inflammatory drug for COVID19 patients alongside with Lopinavir as anti-viral therapy. Furthermore, another therapeutic regime was proposed for COVID-19 patients that rely on using Intravenous immunogloulin (IVIg) and anti-coagulant (low molecular weight heparin) for better recovery from COVID-19 severe and lethal symptoms (Lin et al., 2020).
It is obvious from the presented evidence above that SARS-CoV-2 complications are based on a weakened immune system and local \& systemic inflammation in the body. Hence it is evitable and necessary to look for natural candidate therapies that activate the immune system and reduce inflammation burden in the body. Based on our recent unpublished experiment in a mouse model of osteoarthritis (OA), we have shown that a naturally occurring polysaccharide namely alginate was able to boost immunity and reduce inflammation significantly than the untreated group.

Marine algae are considered as a source of bioactive agents such as alginate, that have a variety of biological characteristics. Alginate is an important naturally occurring polysaccharide that can be found in several marine brown algae such as Macrocystis pyrifera, Laminaria hyperborean and Ascophyllum nodosum (Kurt Ingar Draget, 2005; Szekalska et al., 2016). Based on alginate source, alginate co-polymer can be consists of either $\alpha$-L-guluronic (G- block polymer) or $\beta$-D-mannuronic (M-Blocks polymer) residues or as a mixture of the two blocks (MG) with superior biological characteristics such as solubility, no biological toxicity, gelation and as a scaffold matrix for living cells (Andersen et al., 2015; Wawrzynska et al., 2018).

Alginate extraction is a simple multi-step process that includes the digestion of raw source with diluted mineral acid followed by purification and transformation into salt derivative (sodium or calcium) Expansion in the annual industrial production of alginate is expected to exceed 30000 metric tons with special emphasis on alginate quality refining for mammalian compatibility for pharmaceutical and biomedical applications (Kurt, 2005; Paredes-Juarez et al., 2014).

Physicochemical properties of alginates introduce them as potential candidates for several biomedical applications. They possess mucoadhesive properties, the feasibility of chemical and physical modifications, biocompatibility, no immunogenicity and nontoxicity. 


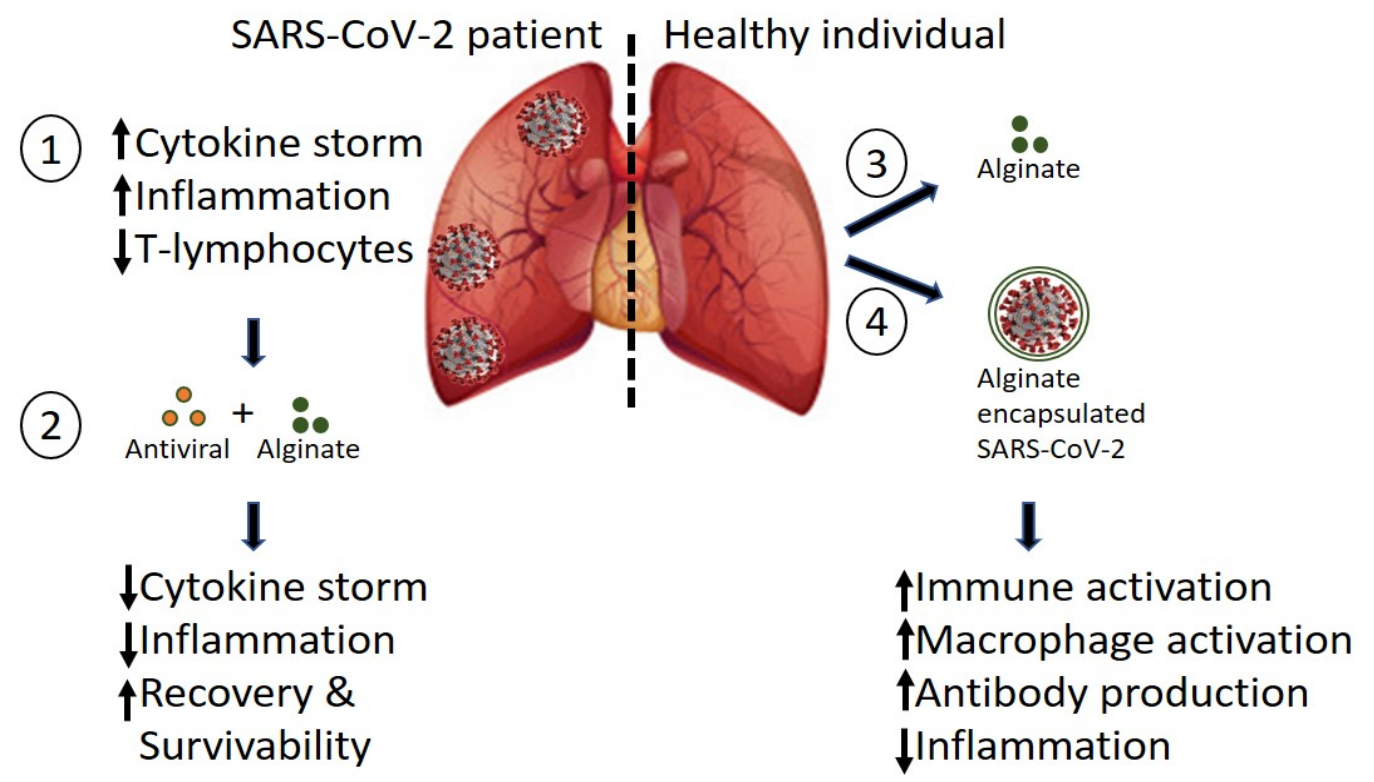

Figure 1. Hypothetical diagram of alginate application to treat Covid-19 patients. 1- Covid-19 patients suffer from dysregulated immune response accompanied by cytokine storm and lymphopenia (decrease in T-lymphocytes). 2- Here we postulate that adding alginate supplement to the anti-viral medications can enhance patient immunity, reduce inflammation and increase recovery and survivability of patients. Alginate supplement can either be administrated to health individual to boost their immune system through macrophage activation (3) or can be used as encapsulation to inactivated SARS-CoV-2 during vaccination routine to enhance body response and specific antibody production (4).

Alginates have been used successfully as an anti-oxidant and anti-inflammatory drug to treat diabetic conditions, hypertension, viral infection (Szekalska et al., 2016) and in wound healing application (Thomas, 2000). In our recent unpublished study on a rat model of osteoarthritis (OA), we have shown that a naturally occurring polysaccharide namely alginate was able to decrease lipid peroxidation, Aggrecanase (ADAMTS4) and concentration of $\beta$-glucouronidase in sera of rats. At the same time, increase antioxidant activity significantly than the untreated group.

In addition, alginate is the only natural marine polysaccharide that possesses a carboxyl group in each sugar ring which is of great importance when incorporating alginate gels with drug cargos (Xing et al., 2020). Alginate oligosaccharides effectively inhibit oxidative stress, modulate the immune response and fight inflammation by free radical scavengers, induce cytokine release and control expression of transcription factor Nuclear Factor Kabba $\mathrm{B}$ (NF-kB). NF-kB is an important regulator of both innate and adaptive immunity (Ge et al., 2018; Xing et al., 2020). Anti-inflammatory activity of alginate oligosaccharide rely on inhibition of nitric oxide (NO) production, prostaglandin E2 (PE2) and cyclooxygenase 2 (COX-2) in RAW264.7 macrophages (Xing et al., 2020). Studies on sulphated alginate derivates have shown that it has a potent antioxidant, antiinflammatory and immune regulatory role on human macrophages. The polymer was superior in superoxide radical's scavenger, regulate IL-6, CXXL8 and TNF- $\alpha$ (Kerschenmeyer et al., 2017). Furthermore, another study indicated that sodium alginate successfully induces the activation of macrophage like-cells invitro through NF-kB pathway activation. This was followed by controlled production of proinflammatory cytokines such as IL-1B, IL-6, IL-12 and TNF- $\alpha$ (Yang et al., 2009). Finally, alginate enriched mannuronate (M-alginate) was found to be a potent inducer for cytokine production than guluronate alginate (Lee et al., 2012) especially induce monocyte and macrophage cytokine production for the treatment of inflammatory diseases and immune-deficient diseases (Ge et al., 2018; Kerschenmeyer et al., 2017; Kurt Ingar Draget, 2005; Yang \& Jones, 2009). 
Administration of chitosan/alginate nanoparticle encapsulated bee venom (CH/AL$\mathrm{BV})$ via the nasal route to pigs after being vaccinated against porcine reproduction and respiratory syndrome virus (PRRSV), could improve their immune response and viral clearance against the virus. This effect was attributed to the high production of $\mathrm{CD}^{+} \mathrm{T}$ lymphocytes, $T$ helper cells and T memory cells (Lee et al., 2018). Similar results were obtained during PR8 influenza virus immunization in mice (Mosafer et al., 2019).

Alginate gels are nano-porous and have been used extensively in dressing applications, wound healing and tissue engineering (Andersen et al., 2015; Lee \& Mooney, 2012) owing to their capability of slow and controlled induction of proinflammatory cytokines (IL-8 and TNF- $\alpha$ ) that help maintaining tissue immune homeostasis (Ge et al., 2018; Wiegand et al., 2009). Alginate gels incorporated with slowrelease low molecular weight heparin were found to induce neovasculature in traumatic tissues by the induction of vascular endothelial growth factor (VEGF) release (Lee et al., 2003) and prevent blood clotting and sepsis (Li et al., 2020).

\section{Recommendation}

Here we hypothetically propose that alginate and alginate derivatives could be used successfully as a therapeutic supplement to moderate and severe infected COVID-19 patients to reduce body inflammation and boost their immune system to reduce blood viremia, decrease lipid peroxidation and increase antioxidant activity. Also, regular daily intake of alginate for healthy individuals could enhance their immune system and may provide additional protection against SARS-CoV-2 infection. Finally, we recommend the use of alginate gels as encapsulation compartment during SARS-CoV-2 vaccination trials to induce a potent immune response and SARS-CoV-2 antibody production.

\section{Funding sources}

This research did not receive any specific grant from funding agencies in the public, commercial, or not-for-profit sectors.

\section{Declaration of Competing Interest}

The authors declare that they have no known competing financial interests or personal relationships that could have appeared to influence the work reported in this paper

\section{Conflict of Interest}

The authors declare no conflict of interest.

\section{References}

Andersen, T., Auk-Emblem, P., Dornish, M. (2015). 3D Cell Culture in Alginate Hydrogels. Microarrays (Basel), 4(2), 133-161. doi:10.3390/microarrays4020133

Channappanavar, R., Perlman, S. (2017). Pathogenic human coronavirus infections: causes and consequences of cytokine storm and immunopathology. Semin Immunopathol, 39(5), 529-539. doi:10.1007/s00281-0170629-x

Choudhary, R., Sharma, A. K., Choudhary, R. (2020). Potential use of hydroxychloroquine, ivermectin and azithromycin drugs in fighting COVID-19: trends, scope and relevance. New Microbes New Infect, 100684. doi:10.1016/j.nmni.2020.100684

Ge, F., Zhu, L., Yang, L., Li, W., Wei, S., Tao, Y., Du, G. (2018). The Soluble and Particulate Form of Alginates Positively Regulate Immune Response. Iran J Immunol, 15(3), 228-238. doi:10.22034/IJI.2018.39392

Ho, S.F.P.a.Y.-C. (2020). SARS-CoV-2: a storm is raging. The Journal of Clinical Investigation, 1$4 . \quad$ doi:Clin Invest. https://doi.org/10.1172/JCI137647.

Jiang, S., Hillyer, C., \& Du, L. (2020). Neutralizing Antibodies against SARS-CoV-2 and Other Human Coronaviruses. Trends Immunol. doi:10.1016/j.it.2020.03.007

Kerschenmeyer, A., Arlov, O., Malheiro, V., Steinwachs, M., Rottmar, M., ManiuraWeber, K., Zenobi-Wong, M. (2017). Antioxidant and immune-modulatory properties of sulfated alginate derivatives on human chondrocytes and macrophages. Biomater Sci, 5(9), 1756-1765. doi:10.1039/c7bm00341b

Kurt, D., Olav, Smidsrùd and Gudmund, Skjåk-Brñk. (2005). Alginates from Algae. In A. S. a. S. K. Rhee (Ed.), Polysaccharides and Polyamides in the Food Industry. Properties, Production, and Patents. (pp. 1-30): WILEY-VCH. 
Kurt Ingar Draget, O.S.a.G.S.-B. (2005). Alginates from Algae. In A. S. a. S. K. Rhee (Ed.), Polysaccharides and Polyamides in the Food Industry. Properties, Production, and Patents. (pp. 1-30): WILEY-VCH.

Lee, J., Kim, Y. M., Kim, J.H., Cho, C.W., Jeon, J.W., Park, J. K., Lee, B. J. (2018). Nasal delivery of chitosan/alginate nanoparticle encapsulated bee (Apis mellifera) venom promotes antibody production and viral clearance during porcine reproductive and respiratory syndrome virus infection by modulating $T$ cell related responses. Vet Immunol Immunopathol, 200, 40-51. doi:10.1016/j.vetimm.2018.04.006

Lee, K.Y., Mooney, D.J. (2012). Alginate: properties and biomedical applications. Prog Polym Sci, $37(1)$, 106-126. doi:10.1016/j.progpolymsci.2011.06.003

Lee, K. Y., Peters, M. C., \& Mooney, D. J. (2003). Comparison of vascular endothelial growth factor and basic fibroblast growth factor on angiogenesis in SCID mice. J Control Release, 87(1-3), 49-56. doi:10.1016/s01683659(02)00349-8

Letko, M., Marzi, A., \& Munster, V. (2020). Functional assessment of cell entry and receptor usage for SARS-CoV-2 and other lineage B betacoronaviruses. Nat Microbiol, 5(4), 562569. doi:10.1038/s41564-020-0688-y

Li, H., Liu, L., Zhang, D., Xu, J., Dai, H., Tang, N., Cao, B. (2020). SARS-CoV-2 and viral sepsis: observations and hypotheses. Lancet. doi:10.1016/S0140-6736(20)30920-X

Lin, L., Lu, L., Cao, W., Li, T. (2020). Hypothesis for potential pathogenesis of SARS-CoV-2 infection-a review of immune changes in patients with viral pneumonia. Emerg Microbes Infect, 9(1), 727-732. doi:10.1080/22221751.2020.1746199

Molina, J. M., Delaugerre, C., Le Goff, J., Mela-Lima, B., Ponscarme, D., Goldwirt, L., de Castro, N. (2020). No evidence of rapid antiviral clearance or clinical benefit with the combination of hydroxychloroquine and azithromycin in patients with severe COVID19 infection. Med Mal Infect. doi:10.1016/j.medmal.2020.03.006

Mosafer, J., Sabbaghi, A.H., Badiee, A., Dehghan, S., Tafaghodi, M. (2019). Preparation, characterization and in vivo evaluation of alginate-coated chitosan and trimethylchitosan nanoparticles loaded with
PR8 influenza virus for nasal immunization. Asian J Pharm Sci, 14(2), 216-221. doi:10.1016/j.ajps.2018.04.005

Paredes-Juarez, G.A., de Haan, B.J., Faas, M.M., de Vos, P. (2014). A Technology Platform to Test the Efficacy of Purification of Alginate. Materials (Basel), 7(3), 2087-2103. doi:10.3390/ma7032087

Szekalska, M., Puciłowska, A., Szymańska, E., Ciosek, P., Winnicka, K. (2016). Alginate: Current Use and Future Perspectives in Pharmaceutical and Biomedical Applications. International Journal of Polymer Science, 2016, 1-17. doi:10.1155/2016/7697031

Thomas, S. (2000). Alginate dressings in surgery and wound management: Part 3. J Wound Care, 9(4), 163-166. doi:10.12968/jowc.2000.9.4.25973

Wawrzynska, E., Kubies, D. (2018). Alginate matrices for protein delivery - a short review. Physiol Res, 67(Suppl 2), S319-S334. doi:10.33549/physiolres.933980

Wen Zhang, Y. Z., Fengchun Zhang, Qian Wang, Taisheng Li, Zhengyin Liu, Jinglan Wang, Yan Qin, Xuan Zhang, Xiaowei, \& Yan, X. Z. a. S. Z. (2019). The use of anti-inflammatory drugs in the treatment of people with severe coronavirus disease 2019 (COVID-19): The experience of clinical immunologists from China. Clinical immunology. doi:https://doi.org/10.1016/j.clim.2020.1083 93

Wiegand, C., Heinze, T., Hipler, U.C. (2009). Comparative in vitro study on cytotoxicity, antimicrobial activity, and binding capacity for pathophysiological factors in chronic wounds of alginate and silver-containing alginate. Wound Repair Regen, 17(4), 511521. doi:10.1111/j.1524-475X.2009.00503.x

Xing, M., Cao, Q., Wang, Y., Xiao, H., Zhao, J., Zhang, Q., Song, S. (2020). Advances in Research on the Bioactivity of Alginate Oligosaccharides. Mar Drugs, 18(3). doi:10.3390/md18030144

Yang, D., \& Jones, K. S. (2009). Effect of alginate on innate immune activation of macrophages. J Biomed Mater Res A, 90(2), 411-418. doi:10.1002/jbm.a.32096

Zhang, D.R.a.Y. (2020). A Mini-review of the 2019 Novel Coronavirus, SARS-CoV-2. American Journal of Biomedical Science \& Research, 8(1), 15-17. 
Zheng, H.Y., Zhang, M., Yang, C.X., Zhang, N., Wang, X. C., Yang, X. P., Zheng, Y. T. (2020). Elevated exhaustion levels and reduced functional diversity of $\mathrm{T}$ cells in peripheral blood may predict severe progression in COVID-19 patients. Cell Mol Immunol. doi:10.1038/s41423-020-0401-3
Zmmer, J.C.a.C. (2020). Bad News Wrapped in Protein: inside the Coronavirus genome. https://www.nytimes.com/interactive/2020/ 04/03/science/coronavirus-genome-badnews-wrapped-in-protein.html 


\section{Egyptian Association for Cancer Research (EACR)}

http://eacr.tanta.edu.eg/

EACR is an NGO society that was declared by the Ministry of Social Solidarity (Egypt) No. 1938 in 19/11/2014 based on the initiative of Prof. Mohamed Labib Salem, the current Chairman of EACR. EACR aims primarily to assist researchers, in particular young researchers in the field of cancer research through workshops, seminars and conferences. Its first international annual conference entitled "Anti-Cancer Drug Discovery" was successfully organized in April 2019 (http://acdd.tanta.edu.eg). Additionally, EACR aims to raise the awareness of the society about the importance of scientific research in the field of cancer research in prediction, early diagnosis and treatment of cancer. EACR is also keen to outreach the scientific community with periodicals and news on cancer research including peer-reviewed scientific journals for the publication of cutting-edge research. The official scientific journal of EACR is "International Journal of Cancer and biomedical Research (IJCBR: https://jcbr.journals.ekb.eg) was successfully issued in 2017 and has been sponsored by the Egyptian Knowledge Bank (EKB: www.ekb.eg).

\section{EACR Chairman,}

Prof. Mohamed Labib Salem, PhD

Professor of Immunology

Faculty of Science, Tanta Universiy, Egypt 


\section{Editor-in-Chief}

Mohamed Labib Salem, PhD

Tanta University, Egypt

\section{Managing Editor}

Nehal Elmashad, MD

Tanta University, Egypt

Nabil Mohy Eldin, PhD

Kafrelsheikh University, Egypt

Doaa Al-Ghareeb, PhD

Alexandria University, Egypt

Abdel-Aziz Zidan, PhD

Damanhour University, Egypt

Wesam Meshrif, PhD

Tanta University, Egypt

Rasha Eraky, MD

Tanta University, Egypt

\section{Associate Editor}

Hesham Tawfik

Tanta University, Egypt

Mostafa El-Sheekh

Tanta University, Egypt

Yousry Albolkiny, PhD

Tanta University, Egypt

Gamal Badr

Assuit University, Egypt

Elsayed Salim

Tanta University, Egypt

Essam Elshiekh

Tanta Cancer Center, Egypt

\section{Editorial Board}

\author{
Alberto Montero \\ Taussig Cancer Center, \\ Cleveland, USA \\ Marcela Diaz \\ Cleveland Clinic Foundation, USA \\ Yi Zhang \\ Zhengzhou University, China \\ Shengdian Wang \\ Chinese Academy of Sciences, \\ China \\ Faris Alenzi \\ Prince Sattam bin Abdulaziz \\ University, KSA \\ Mark Robunstein \\ Medical University of South \\ Carolina, USA \\ Mamdooh Ghoneum, DSc \\ Charles Drew University of \\ Medicine \& Science, USA
}

Natarajan Muthusamy, DVM

The Ohio State University, USA

Hideki Kasuya MD, PhD,

FACS

Nagoya University, Japan

Sherif El-Khamisy, MD

Sheffield University, UK

Mohamed Abou-El-Enein,

MD

Charité Universitätsmedizin

Berlin, Germany

Alaa Eldin Almostafa, MD

McGill University, Canada

Amr Amin

United Arab Emirates

University, UAE

AbdeIRahman Zekri

National Cancer Institute, Egypt

Mohamed Attia, MD

Tanta University, Egypt

Mohamed Elshanshory, MD

Tanta University, Egypt

Hussein Khamis

Alexandria University, Egypt

Magdy Mahfouz

Kafr Elsheikh University, Egypt

Ehab Elbedewey

Tanta University, Egypt

Abeer Badr

Cairo University, Egypt

Nadia Hamdy, PharmD

Ain Shams University, Egypt

Ibrahim El-Sayed

Menoufia University, Egypt

Tarek Aboul-Fadl, PharmD

Assiut University, Egypt

Mohamed Noureldin

Banaha University, Egypt

Haiam Abou Elela

National Institute of

Oceanography and Fisherie,

Egypt

Sameh Ali, MD

Nationa Liver Institute, Egypt

Maha EL-Demellawi

City for Scientific Research \&

Technology Applications, Egypt

Desouky A Abd-El-Haleem

City for Scientific Research \&

Technology Applications, Egypt
Ashraf Tabll

National Research Center, Egypt

Wael Lotfy, MD

Alexandria University, Egypt

Olfat Gadallah, MD

Tanta University, Egypt

Nahla Shoukry

Suez University, Egypt

Medhat Eldenary

Tanta University, Egypt

Nagla Sarhan, MD

Tanta University, Egypt

Naglaa Fathy, MD

Zagazik University, Egypt

Azza Hasan Mohamed Menufia University, Egypt

Nanees Gamal Eldin

Tanta University, Egypt

Mohamed Mansour, UK

Sabbah Hammoury

Alexandria Ayadi Almostaqbal

Oncology Hospital, Egypt

Nehal Aboulfotoh

Zewail City for Science and

Technology, Cairo, Egypt

Amir Elkhami

Galaxo, San Francisco, USA

Rabab Khairat

National Research Center,

Giza, Egypt

Ahmed Alzohairy

Zagazi University, Egypt

Wgady Khalil

National Research Center, Egypt

Sayed Bakry

Alazhar University, Egypt

Mohamed Ghanem, MD

Kafr Elshikh University, Egypt

Mohamed Salama, MD

Mansoura University, Egypt

Mona Marie, MD

Alexandria University, Egypt

\section{For more information, contact}

Hamdi Kandil

Tanta University, Egypt

Email: ljcbr100@gmail.com 